\title{
Identification of long non-coding RNA CCAT1 as an oncogene in nasopharyngeal carcinoma
}

\author{
YAMENG DONG $^{1}$, HAOZHAN YUAN ${ }^{2}$ and GUANGYU JIN ${ }^{1}$ \\ ${ }^{1}$ Department of Otolaryngology, The Nuclear Industry 215 Hospital of Shaanxi Province; \\ ${ }^{2}$ Department of Otolaryngology, The First People's Hospital of Xianyang, Xianyang, Shaanxi 712000, P.R. China
}

Received July 24, 2016; Accepted May 14, 2018

DOI: $10.3892 / 01.2018 .8969$

\begin{abstract}
Nasopharyngeal carcinoma (NPC) is a common type of cancer worldwide. Long non-coding RNAs (lncRNAs) have been demonstrated to be associated with the development of multiple types of human cancer. The present study aimed to identify the potential role of lncRNA colon cancer associated transcript 1 (CCAT1) in NPC. Reverse transcription-quantitative polymerase chain reaction (RT-qPCR) was used to detect the expression levels of CCAT1 in NPC tissues and cell lines. The function of CCAT1 in the proliferation, migration, invasion and apoptosis of NPC cells was detected by MTT, cell scratch, Transwell, flow cytometry and caspase-3 ELISA assays, respectively. The results indicated that the expression levels of CCAT1 were significantly upregulated in NPC tissues compared with normal nasopharyngeal epithelial tissues. CCAT1 expression was also higher in SUNE-1 and C666-1 cells compared with NP69 cells. Furthermore, the knockdown of CCAT1 was indicated to inhibit growth, migration and invasion, and induce apoptosis in NPC cells. In conclusion, the present study is, to the best of our knowledge, the first to provide new findings that support an oncogenic role of CCAT1 in NPC. Further research is required to define the potential molecular mechanism of CCAT1 in the development of NPC.
\end{abstract}

\section{Introduction}

Nasopharyngeal carcinoma (NPC) arises from the epithelial cells of the nasopharynx and it is highly locally transferable and aggressive $(1,2)$. At present, the treatment is radiotherapy at early-stage of NPC and chemo-radiotherapy at advanced stage of the disease $(3,4)$. Pathophysiological studies on the development of NPC have indicated that Epstein-Barr virus

Correspondence to: Mr. Guangyu Jin, Department of Otolaryngology, The Nuclear Industry 215 Hospital of Shaanxi Province, 35 Weiyang West Road, Xianyang, Shaanxi 712000, P.R. China

E-mail: jgy215dr@163.com

Key words: nasopharyngeal carcinoma, long non-coding RNA, colon cancer associated transcript 1 , oncogene infection, genetic susceptibility and environmental factors are the main etiological factors (5-7). However, the exact mechanisms involved in the progression of NPC have remained to be fully illustrated. Therefore, it is essential to determine the underlying molecular mechanisms of NPC and identify new biomarker for developing novel therapeutic strategies against NPC.

Long noncoding RNAs (lncRNAs) are >200 nucleotides in length and cannot be translated into proteins (8-10). Studies have demonstrated that IncRNAs are involved in various cellular biological processes, including cell proliferation, cell migration, cell cycle and cell apoptosis (11-13). Notably, some lncRNAs are dysregulated and contribute to the development of human cancer. For example, Gupta et al (14) reported that HOX transcript antisense RNA was upregulated and promoted cell metastasis by interacting with the polycomb repressive complex 2 in breast cancer. Shi et al (15) indicated that the downregulation of growth arrest specific 5 was involved in the tumorigenesis and progression of lung cancer. Zhang et al (16) suggested that antisense RNA in the INK4 locus 2 was upregulated in human gastric cancer and was associated with tumor progression.

In the present study, the authors intended to investigate the expression and role of IncRNA colon cancer associated transcript 1 (CCAT1) in NPC. First, the expression levels of CCAT1 in NPC tissues and cell lines were assessed. Furthermore, the cell proliferation, migratory, invasive and apoptotic abilities following the knockdown of CCAT1 in NPC cells were examined. The present study indicates a considerable step forward in understanding the importance of lncRNAs in NPC and provides a novel insight concerning the role of CCAT1 in the progression and development of NPC.

\section{Materials and methods}

NPC samples. A total of 35 nasopharyngeal carcinoma tissues from patients $(53.4 \pm 6.3$ years old; $57.8 \%$ male) with NPC and 20 normal nasopharyngeal epithelial tissues from healthy individuals $(50.9 \pm 5.7$ years old; $51.3 \%$ men $)$ were obtained from the Nuclear Industry 215 Hospital of Shaanxi Province (Xianyang, China) between January 2010 and June 2015. None of the patients acquired radiotherapy or chemotherapy prior to surgery. The tissue samples were confirmed by histopathological examination in the Nuclear Industry 215 Hospital of 
Shaanxi Province. All specimens were frozen in liquid nitrogen and subsequently stored at $-80^{\circ} \mathrm{C}$ for further study. Informed consent was obtained from each participant. The present study was also approved by the hospital Research Ethics Board of the Nuclear Industry 215 Hospital of Shaanxi Province.

Cell culture and transfection. The human NPC cell lines (SUNE-1 and C666-1) and human nasopharyngeal epithelial cell line (NP69) were obtained from Southern Medical University (Guangzhou, China). SUNE-1, C666-1 and NP69 cells were cultured in DMEM, RPMI-1640 and keratinocyte serum-free medium (Gibco; Thermo Fisher Scientific, Inc., Waltham, MA, USA), respectively, and supplemented with $10 \%$ fetal bovine serum (FBS; Gibco; Thermo Fisher Scientific, Inc., Waltham, MA, USA), $100 \mu / \mathrm{ml}$ penicillin and $100 \mathrm{mg} / \mathrm{ml}$ streptomycin a humidified incubator with $5 \% \mathrm{CO}_{2}$ atmosphere at $37^{\circ} \mathrm{C}$.

The small interfering RNA (siRNA) targeting CCAT1 (si-CCAT1; 5'-AGGGAAACAGGAGCAAUCAUCATT A-3') and corresponding siRNA negative control (si-NC; 5'-UUCUCCGAACGUGUCACGUTT-3') were designed and purchased from Shanghai GenePharma Co., Ltd., (Shanghai, China). For CCAT1 knockdown, the cells were seeded at $37^{\circ} \mathrm{C}$ overnight and transfected with either $50 \mathrm{nM}$ si-CCAT1 or si-NC using Lipofectamine ${ }^{\circledR} 2000$ (Invitrogen; Thermo Fisher Scientific, Inc.) following the manufacturer's protocols. The cells were harvested and total RNA was isolated for quantitative polymerase chain reaction (qPCR) analysis $24 \mathrm{~h}$ after transfection.

$R N A$ extraction and reverse transcription (RT)-qPCR. The TRIzol solution (Invitrogen; Thermo Fisher Scientific, Inc.) was used to isolate total RNA from NPC tissues and cells. Total RNA samples with 260/280 ratios at 1.8-2.1 were selected for further experiment. Then, the RNA was converted into cDNA by using the Super-Script III RT (Invitrogen; Thermo Fisher Scientific, Inc.). The expression levels of CCAT1 was detected by using a SYBR ${ }^{\circledR}$ Premix Ex TaqTM II kit (Takara Bio, Inc., Otsu, Japan) on the LightCycler 480 Real-Time PCR system (Roche Molecular Diagnostics, Pleasanton, CA, USA). The conditions of qPCR were as follows: $94^{\circ} \mathrm{C}$ for $15 \mathrm{~min}$, followed by 45 cycles of $94^{\circ} \mathrm{C}$ for $10 \mathrm{sec}, 60^{\circ} \mathrm{C}$ for $30 \mathrm{sec}$, and $72^{\circ} \mathrm{C}$ for $30 \mathrm{sec}$. The sequence of the CCAT1 forward primer was 5'-TTTATGCTTGAGCCTTGA-3' and reverse primer was 5'-CTTGCCTGAAATACTTGC-3'. The sequence of the Actb forward primer was 5'-GGCACCACACCTTCTACAATGA-3' and reverse primer was 5'-GGATAGCACAGCCTGGAT AGC-3'. The $2^{-\Delta \Delta C q}$ method was used to quantify the relative CCAT1 expression (17).

Cell proliferation assay. Human SUNE-1 and C666-1 cells were seeded in 96 -well plates $\left(\sim 5 \times 10^{3}\right.$ cells/well). Following transfection for four time points $(0,24,48$ and $72 \mathrm{~h}), 20 \mu \mathrm{l}$ MTT (5 mg/ml; Sigma-Aldrich; Merck KGaA, Darmstadt, Germany) solution was added into cells and incubated at $37^{\circ} \mathrm{C}$ in a humidified chamber with $5 \% \mathrm{CO}_{2}$ for $4 \mathrm{~h}$. Subsequently, $150 \mu 1$ DMSO (DMSO; Sigma-Aldrich; Merck KGaA) was added to each well and incubated at room temperature for 10-15 min. The absorbance was detected by using an ELISA microplate reader (Model 680; Bio-Rad Laboratories, Inc.,
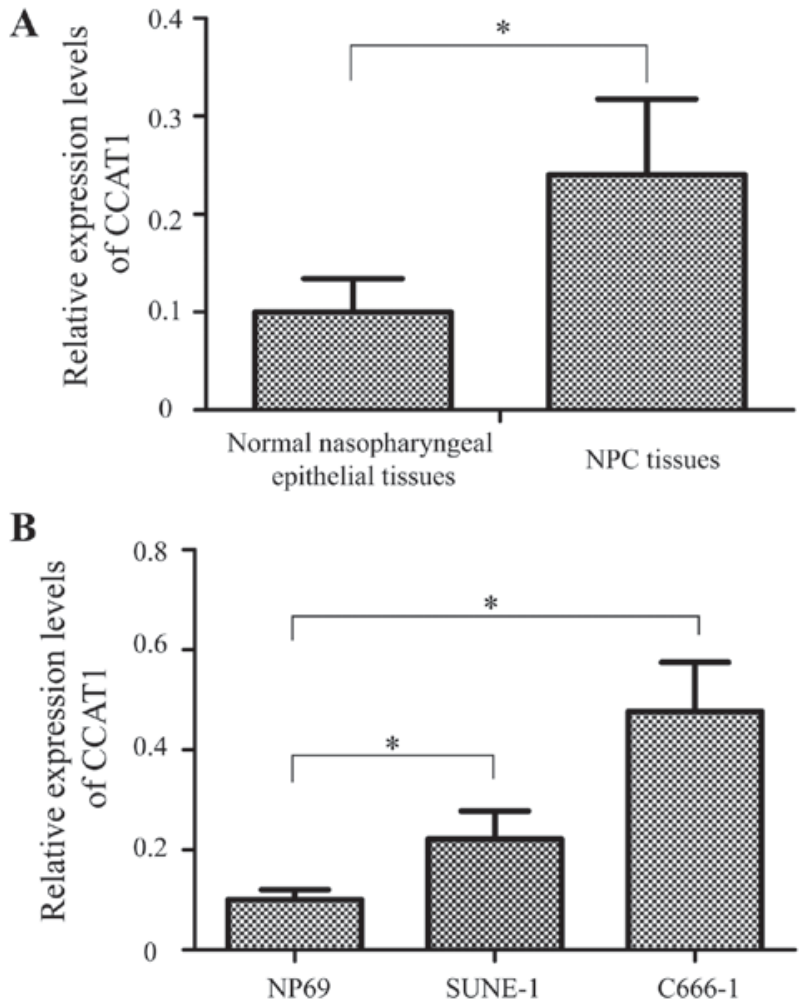

Figure 1. Upregulation of CCAT1 expression in NPC tissues and cell lines. (A) RT-qPCR indicated that CCAT1 was upregulated in NPC tissues compared with normal nasopharyngeal epithelial tissues. (B) CCAT1 expression was higher in SUNE-1 and C666-1 cells compared with NP69 cells RT-qPCR, reverse transcription-quantitative polymerase chain reaction. ${ }^{*} \mathrm{P}<0.05$. CCAT1, colon cancer associated transcript 1 ; NPC, nasopharyngeal carcinoma.

Hercules, CA, USA) at a wavelength of $480 \mathrm{~nm}$ with $630 \mathrm{~nm}$ as the reference wavelength. The experiments were performed in triplicate.

Cell scratch assay. Cell scratch assay was used to determine the migratory ability of NPC cells. A total of $\sim 5 \times 10^{5}$ SUNE-1 and C666-1 cells were seeded on 6-well plates for overnight at $37^{\circ} \mathrm{C}$ in a humidified chamber with $5 \% \mathrm{CO}_{2}$. Then, the SUNE-1 and C666-1 cells were transfected with either si-CCAT1 or si-NC when the cells were grown to $70-75 \%$ confluence. A sterile $100 \mu \mathrm{l}$ pipette tip was used to scrape three clear lines through the cell layer $6 \mathrm{~h}$ after transfection. A light microscope (DM4000B; Leica Microsystems GmbH, Wetzlar, Germany) was used to observe the migration distance at 0 and $24 \mathrm{~h}$ (magnification, x200). Assays were repeated at least three times.

Transwell invasion assay. For the invasion assay, $2 \times 10^{5}$ SUNE-1 and C666-1 cells were plated in the top chamber onto the Matrigel coated membrane (BD Biosciences, Franklin Lakes, NJ, USA), and cultured with DMEM or RPMI-1640 medium. DMEM or RPMI-1640 medium containing 10\% FBS was added to the lower chamber and served as the chemoattractant. Following incubation at $37^{\circ} \mathrm{C}$ in a humidified chamber with $5 \% \mathrm{CO}_{2}$ for $48 \mathrm{~h}$, the cells that did not invade were removed from the upper chamber, and the cells that have invaded on the lower membrane surface were fixed 
A

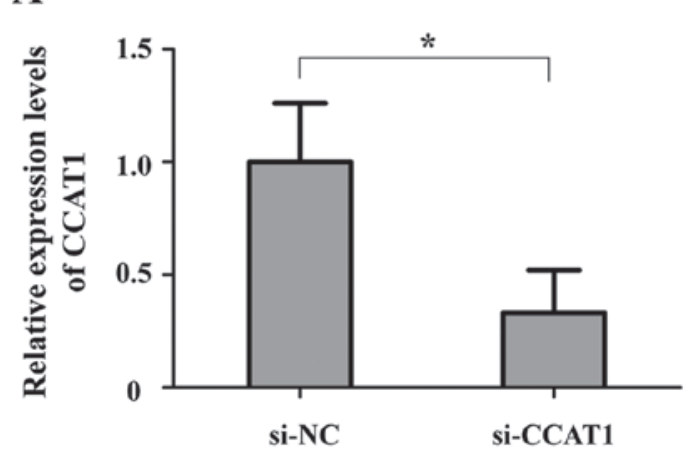

B

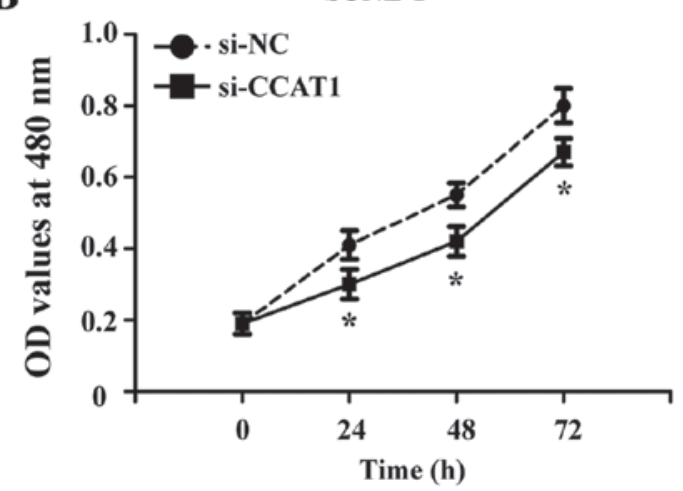

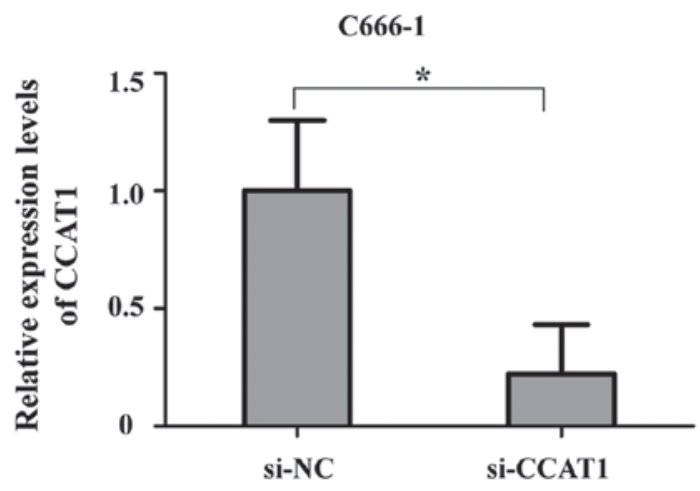

C666-1

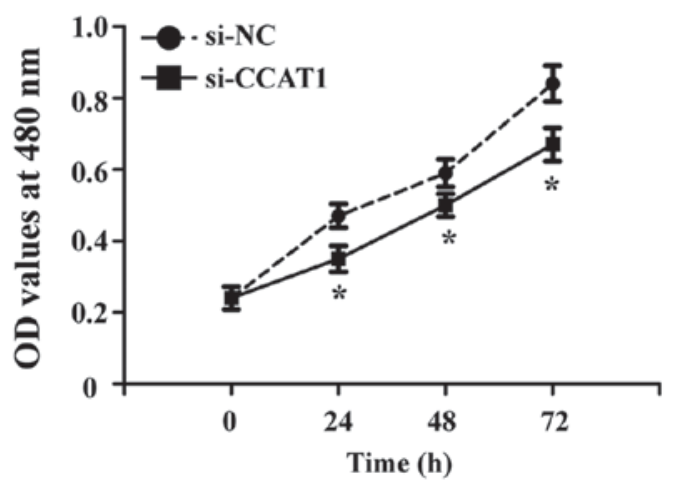

Figure 2. Proliferation of NPC cells is inhibited in vitro via suppression of CCAT1. (A) Validation of transfection efficiency of NPC cells following transfection with si-CCAT1 or si-NC. (B) The proliferation of NPC cells was measured by MTT assay at different time intervals. "P<0.05. CCAT1, colon cancer associated transcript 1; si, siRNA; NC, negative control; NPC, nasopharyngeal carcinoma; OD, optical density.

in methanol, stained with $0.1 \%$ crystal violet (Sigma-Aldrich; Merck KGaA) at $37^{\circ} \mathrm{C}$ and counted using a DM4000B microscope (magnification $\mathrm{x} 200$ ). Each experiment was performed at least three times.

Cell apoptosis assay. For cell apoptosis analysis, $\sim 5 \times 10^{5}$ SUNE-1 and C666-1 cells were seeded on 6-well plates for overnight in a humidified chamber with $5 \% \mathrm{CO}_{2}$ at $37^{\circ} \mathrm{C}$. After $48 \mathrm{~h}$ transfection, the cells were collected and washed twice with cold PBS. Then, the cells were re-suspended with $1 \mathrm{X}$ binding solution (Invitrogen; Thermo Fisher Scientific, Inc.) and stained with annexin V-fluorescein isothiocyanate (annexin V; $5 \mu \mathrm{l}$; Invitrogen; Thermo Fisher Scientific, Inc.) and propidium iodide (PI, $3 \mu 1$; Invitrogen; Thermo Fisher Scientific, Inc.). Finally, a flow cytometer (EPICS, X1-4; Beckman Coulter, Inc., Brea, CA, USA) was used to detect the percentage of apoptotic cells after mixing for $20 \mathrm{~min}$ at $37^{\circ} \mathrm{C}$. The experiments were performed in triplicate.

Caspase 3 ELISA assay. Human SUNE-1 and C666-1 cells were transfected with si-CCAT1 or si-NC $48 \mathrm{~h}$ after transfection. Apoptosis that was induced by CCAT1 silencing was determined by calculating the activity of caspase- 3 using a caspase-3 ELISA assay kit (Invitrogen; Thermo Fisher Scientific, Inc.) according to the manufacturer's protocols. Optical density (OD) values were measured by using an ELISA microplate reader (Model 680; Bio-Rad Laboratories, Inc.).
Statistical analysis. Statistical analysis was analyzed by using SPSS statistical software (version 18.0; SPSS, Inc., Chicago, IL, USA). All data were presented as the mean \pm standard deviation from at least three independent experiments. The differences between groups were analyzed by using Student's $\mathrm{t}$-test or one-way analysis of variance. $\mathrm{P}<0.05$ was considered statistically significant.

\section{Results}

CCATl expression is upregulated in NPC tissues and cell lines. The expression levels of CCAT1 were examined in 35 NPC tissues and 20 non-tumor tissues by RT-qPCR assay. As indicated in Fig. 1A, the expression of CCAT1 was markedly upregulated in NPC tissues compared with normal nasopharyngeal epithelial tissues $(\mathrm{P}<0.05)$.

The expression levels of CCAT1 were also examined in two NPC cells (SUNE-1 and C666-1) and the normal nasopharyngeal epithelial cell line (NP69). As indicated in Fig. 1B, CCAT1 expression was higher in SUNE-1 and C666-1 cells compared with NP69 cells $(\mathrm{P}<0.05)$.

CCAT1 suppression inhibits the proliferation of NPC cells in vitro. To examine the role of CCAT1 in the development of NPC, SUNE-1 and C666-1 cells were transfected with si-CCAT1 or si-NC by using Lipofectamine ${ }^{\circledR} 2000$. As indicated in Fig. 2A, CCAT1 expression in SUNE-1 and C666-1 cells was significantly downregulated following transfection with si-CCAT1 compared with 
A
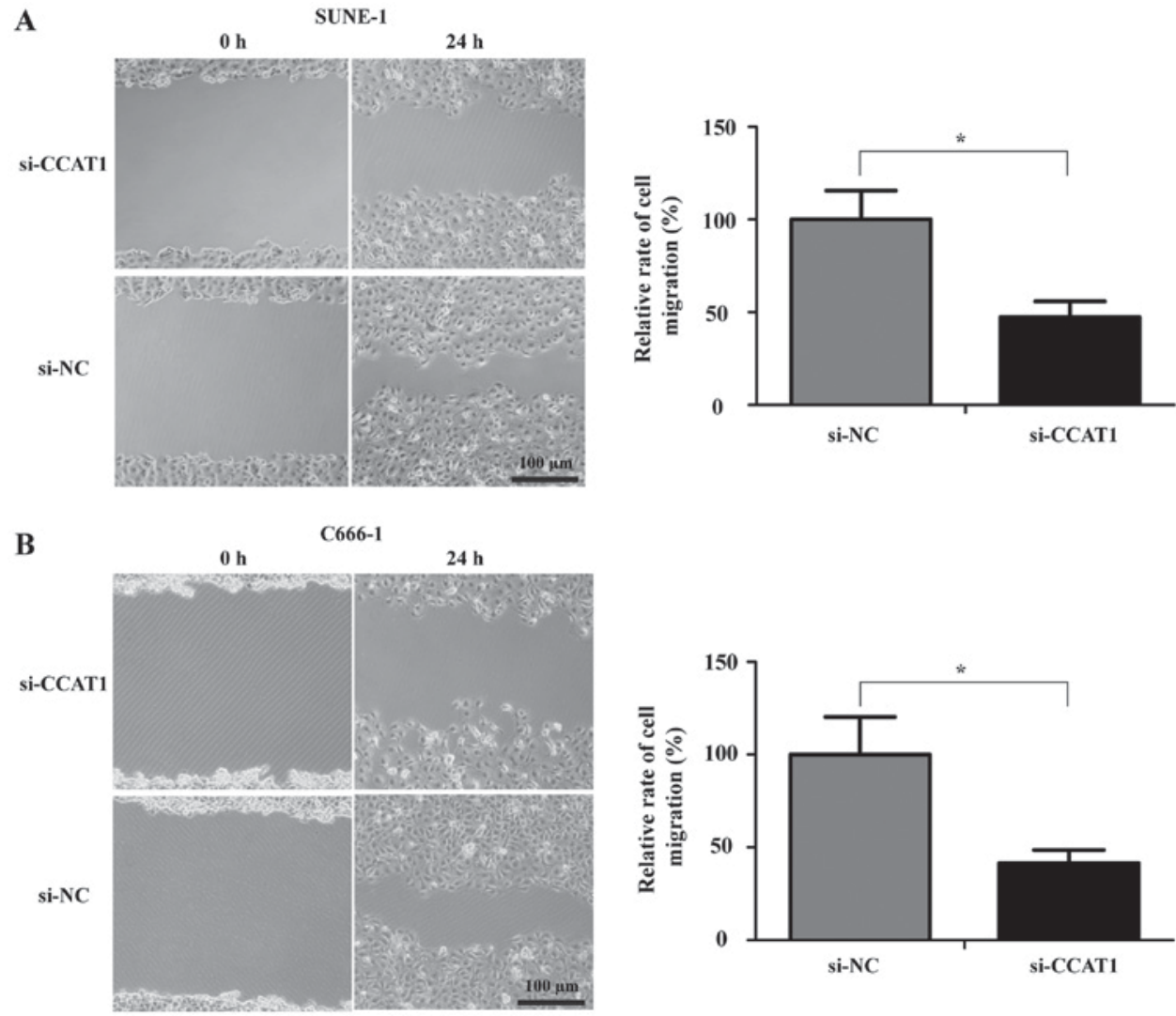

Figure 3. CCAT1 knockdown inhibits the migration of NPC cells in vitro. (A) Cell scratch assay was used to determinate the migratory ability of SUNE-1 cells following transfection with si-CCAT1 or si-NC. (B) The migratory ability of C666-1 cells that were transfected with si-CCAT1 was decreased significantly compared with the cells that were treated with si-NC. Magnification x200. ${ }^{*} \mathrm{P}<0.05$. CCAT1, colon cancer associated transcript 1; si, siRNA; NC, negative control; NPC, nasopharyngeal carcinoma.

the si-NC group $(\mathrm{P}<0.05)$. Furthermore, the effect of CCAT1 on the growth ability of NPC cells was checked by MTT assay. The results showed that proliferation ability of NPC cells was significantly reduced after treatment with si-CCAT1 compared with the si-NC group ( $\mathrm{P}<0.05$; Fig. 2B).

CCAT1 knockdown inhibits the migration and invasion of NPC cells in vitro. Cell migration was examined by cell scratch assay. The results revealed that the migratory ability of NPC cells that were transfected with si-CCAT1 was decreased significantly compared with the cells that were treated with si-NC. The relative rate of migration was $47.3 \pm 8.4 \%$ for si-CCAT1-transfected SUNE-1 cells $(\mathrm{P}<0.05$; Fig. 3A), and 41.5 $\pm 7.1 \%$ for si-CCAT1-transfected C666-1 cells $(\mathrm{P}<0.05$; Fig. 3B).

Transwell assay was also used to detect the invasion of NPC cells following transfection with si-CCAT1 or si-NC. The results indicated that the knockdown of CCAT1 inhibited the invasion of SUNE-1 and C666-1 cells $(\mathrm{P}<0.05$; Fig. 4).

Targeting CCAT1 induces the apoptosis of NPC cells in vitro. To investigate the effect of CCAT1 on the apoptosis of NPC cells, flow cytometric assay was performed (Fig. 5). SUNE-1 and C666-1 cells were transfected with si-CCAT1 or si-NC. As shown in Fig. 5A and C, the apoptotic rate was increased significantly in the SUNE-1 cells

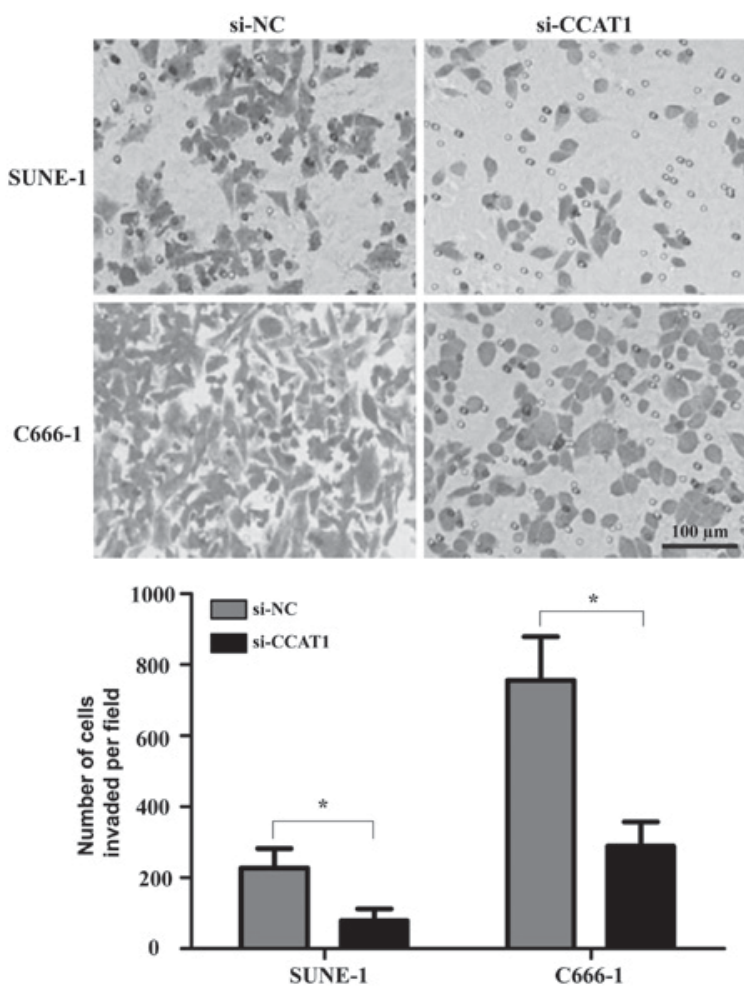

Figure 4. CCAT1 knockdown inhibits the invasion of NPC cells in vitro. Transwell invasion assay was used to determinate the invasive ability of NPC cells following transfection with si-CCAT1 or si-NC. Magnification $\mathrm{x} 200 .{ }^{*} \mathrm{P}<0.05$. CCAT1, colon cancer associated transcript 1 ; si, siRNA; $\mathrm{NC}$, negative control; NPC, nasopharyngeal carcinoma. 

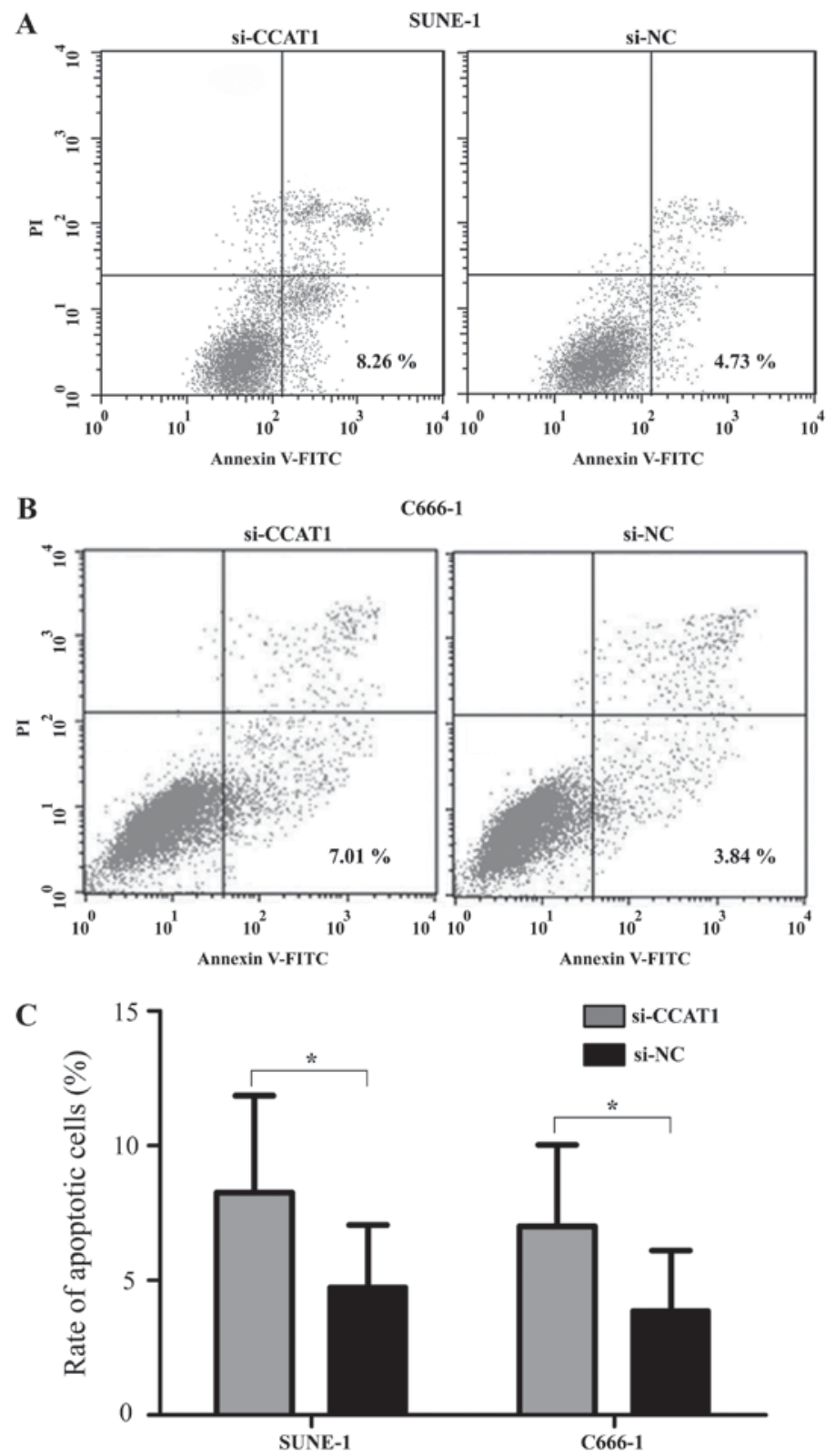

Figure 5. Targeting CCAT1 induces the apoptosis of NPC cells in vitro. (A) The apoptosis rates were assessed by flow cytometric analysis after SUNE-1 cells were treated with si-CCAT1 or si-NC. (B) Effect of CCAT1 on the apoptosis of C666-1 cells. (C) Comparison of the apoptotic rates of SUNE-1 and C666-1 cells following transfection with si-CCAT1 or si-NC. "P<0.05. CCAT1, colon cancer associated transcript 1; FITC, fluorescein isothiocyanate; NC, negative control; NPC, nasopharyngeal carcinoma; si, siRNA.

that were transfected with si-CCAT1 compared with the si-NC group $(\mathrm{P}<0.05)$. Additionally, the apoptotic rate of C666-1 cells that were treated with si-CCAT1 was markedly higher compared with cells that were transfected with si-NC $(\mathrm{P}<0.05$; Fig. 5B and $\mathrm{C})$. The relative activity of caspase- 3 was determined by caspase-3 ELISA assay $48 \mathrm{~h}$ after transfection. Consistent with the data from flow cytometry assay, the relative activity of caspase-3 was increased in SUNE-1 and C666-1 cells that were treated with si-CCAT1 compared with the si-NC group $(\mathrm{P}<0.05$; Fig. 6).

\section{Discussion}

Recently, novel treatment strategies have been developed for NPC, including molecular targeted therapy,

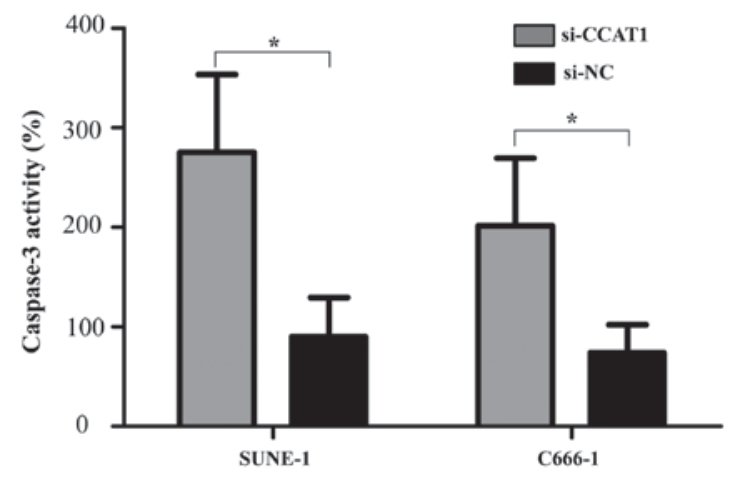

Figure 6. Apoptosis of NPC cells as determined by caspase-3 ELISA assay. The relative activity of caspase-3 was increased in SUNE-1 and C666-1 cells that were treated with si-CCAT1 compared with the cells that were treated with si-NC. ${ }^{*} \mathrm{P}<0.05$. CCAT1, colon cancer associated transcript 1 ; NC, negative control; NPC, nasopharyngeal carcinoma; si, siRNA. 
immunotherapy and gene therapy (18). However, the long-term prognosis of NPC is still poor due to local recurrence and early metastasis, and NPC remains a major public health concern $(18,19)$. A growing number of studies have been focused on the function of dysregulated lncRNAs in various human cancers $(20,21)$. An increasing number of studies have showed that the aberrant expression of lncRNAs are involved in cell proliferation, metastasis and apoptosis in NPC. For instance, Li et al (22) reported that long non-coding RNA H19 regulates enhancer of zeste 2 polycomb repressive complex 2 subunit expression by interacting with miRNA (miR)-630 and promoting cell invasion in NPC. Gong et al (23) revealed that LOC401317 inhibited cell growth and activated apoptosis in NPC cells. Lu et al (24) illustrated that nuclear paraspeckle assembly transcript 1 regulated epithelial to mesenchymal transition and radioresistance in via the miR-204/ZEB1 axis in NPC. Therefore, the identification of novel lncRNAs expression signatures in the progression and development of NPC will be helpful to identify novel diagnostic and therapeutic biomarkers for NPC in the future.

CCAT1 is a recently identified lncRNA with 2628 nucleotide in length, which is located in the vicinity of a well-known transcription regulator, c-Myc (25). Previous studies have demonstrated that CCAT1 was significantly upregulated in colon cancer tissues when compared with matched normal tissues (26). The expression of CCAT1 was also indicated to be upregulated in patients with breast cancer tissues compared with adjacent normal tissues (27). In the present study, the expression of CCAT1 in NPC tissues and normal nasopharyngeal epithelial tissues were compared. Consistent with the upregulation of CCAT1 in breast cancer and colon carcinoma from previous reports $(26,27)$, the data from the present study demonstrated that CCAT1 was also upregulated in NPC tissues in comparison with normal nasopharyngeal epithelial tissues.

Previous studies have also reported that CCAT1 promoted the cell proliferation and invasion of hepatocellular carcinoma cells (28). InRNA CCAT1 also regulated the development of gallbladder cancer via negative regulation of microRNA-218-5p (29). C-Myc-activated lnRNA CCAT1 induced the proliferation and invasion of colon cancer cells (30). In the present study, the role of CCAT1 in NPC cells by applying was examined using loss-of-function experiments. Accordingly, the present study revealed that the inhibition of CCAT1 suppressed the proliferation, migration and invasion of NPC cells, and induced the apoptosis of NPC cells. Therefore, the present data indicated that CCAT1 acts as an oncogene in NPC.

In conclusion, the present study is the first to confirm that CCAT1 expression was upregulated in NPC tissues and cell lines. It was also indicated that the knockdown of CCAT1 significantly suppressed the growth, migratory and invasive abilities of NPC cells, and promoted cell apoptosis, suggesting CCAT1 might be a promising biomarker for molecularly targeted therapy of NPC.

\section{Acknowledgements}

Not applicable.

\section{Funding}

No funding was received.

\section{Availability of data and materials}

The datasets used and/or analyzed during the current study are available from the corresponding author on reasonable request.

\section{Authors' contributions}

YD and GJ designed and carried out the experiments. YD and HY analyzed the data. YD and GJ wrote and revised the manuscript.

\section{Ethics approval and consent to participate}

The present study was approved by the ethics committee of the Nuclear Industry 215 Hospital of Shaanxi Province. Written informed consent was obtained from all patients prior to the start of the study.

\section{Consent for publication}

Written informed consent was obtained from all patients prior to the start of the study.

\section{Competing interests}

The authors declare that they have no competing interest.

\section{References}

1. Wei WI and Sham JS: Nasopharyngeal carcinoma. Lancet 365: 2041-2054, 2005

2. Torre LA, Bray F, Siegel RL, Ferlay J, Lortet-Tieulent J and Jemal A: Global cancer statistics, 2012. CA Cancer J Clin 65: 87-108, 2015.

3. Ma BB, Hui EP and Chan AT: Systemic approach to improving treatment outcome in nasopharyngeal carcinoma: Current and future directions. Cancer Sci 99: 1311-1318, 2008.

4. Perri F, Dell'Oca I, Muto P, Schiavone C, Aversa C, Fulciniti F, Solla R, Scarpati GD, Buonerba C, Di Lorenzo G and Caponigro F: Optimal management of a patient with recurrent nasopharyngeal carcinoma. World J Clin Cases 2: 297-300, 2014.

5. Zeng Z, Huang H, Zhang W, Xiang B, Zhou M, Zhou Y, Ma J, Yi M, Li X, Li X, et al: Nasopharyngeal carcinoma: Advances in genomics and molecular genetics. Sci China Life Sci 54: 966-975, 2011.

6. Burgos JS: Involvement of the Epstein-Barr virus in the nasopharyngeal carcinoma pathogenesis. Med Oncol 22: 113-121, 2005.

7. Lo KW, To KF and Huang DP: Focus on nasopharyngeal carcinoma. Cancer Cell 5: 423-428, 2004.

8. Johnsson P and Morris KV: Expanding the functional role of long noncoding RNAs. Cell Res 24: 1284-1285, 2014.

9. Lau E: Non-coding RNA: Zooming in on lncRNA functions. Nat Rev Genet 15: 574-575, 2014.

10. Ponting CP, Oliver PL and Reik W: Evolution and functions of long noncoding RNAs. Cell 136: 629-641, 2009.

11. Gibb EA, Brown CJ and Lam WL: The functional role of long non-coding RNA in human carcinomas. Mol Cancer 10: 38, 2011.

12. Wilusz JE, Sunwoo H and Spector DL: Long noncoding RNAs: Functional surprises from the RNA world. Genes Dev 23: 1494-1504, 2009.

13. Ørom UA, Derrien T, Beringer M, Gumireddy K, Gardini A, Bussotti G, Lai F, Zytnicki M, Notredame C, Huang Q, et al: Long noncoding RNAs with enhancer-like function in human cells. Cell 143: 46-58, 2010 
14. Gupta RA, Shah N, Wang KC, Kim J, Horlings HM, Wong DJ, Tsai MC, Hung T, Argani P, Rinn JL, et al: Long non-coding RNA HOTAIR reprograms chromatin state to promote cancer metastasis. Nature 464: 1071-1076, 2010.

15. Shi X, Sun M, Liu H, Yao Y, Kong R, Chen F and Song Y: A critical role for the long non-coding RNA GAS5 in proliferation and apoptosis in non-small-cell lung cancer. Mol Carcinog 54 (Suppl 1): E1-E12, 2015

16. Zhang EB, Kong R, Yin DD, You LH, Sun M, Han L, Xu TP, Xia R, Yang JS, De W and Chen JF: Long noncoding RNA ANRIL indicates a poor prognosis of gastric cancer and promotes tumor growth by epigenetically silencing of miR-99a/miR-449a. Oncotarget 5: 2276-2292, 2014.

17. Livak KJ and Schmittgen TD: Analysis of relative gene expression data using real-time quantitative PCR and the 2(-Delta Delta C(T)) method. Methods 25: 402-408, 2001

18. Spratt DE and Lee N: Current and emerging treatment options for nasopharyngeal carcinoma. Onco Targets Ther 5: 297-308, 2012.

19. Wei WI and Kwong DL: Current management strategy of nasopharyngeal carcinoma. Clin Exp Otorhinolaryngol 3: 1-12, 2010.

20. Yang G, Lu X and Yuan L: LncRNA: A link between RNA and cancer. Biochim Biophys Acta 1839: 1097-1109, 2014.

21. Gong Z, Zhang S, Zhang W, Huang H, Li Q, Deng H, Ma J, Zhou M, Xiang J, Wu M, et al: Long non-coding RNAs in cancer. Sci China Life Sci 55: 1120-1124, 2012.

22. Li X, Lin Y, Yang X, Wu X and He X: Long noncoding RNA $\mathrm{H} 19$ regulates EZH2 expression by interacting with miR-630 and promotes cell invasion in nasopharyngeal carcinoma. Biochem Biophys Res Commun 473: 913-919, 2016.

23. Gong Z, Zhang S, Zeng Z, Wu H, Yang Q, Xiong F, Shi L, Yang J, Zhang W, Zhou Y, et al: LOC401317, a p53-regulated long non-coding RNA, inhibits cell proliferation and induces apoptosis in the nasopharyngeal carcinoma cell line SUNE-1. PLoS One 9: e110674, 2014.
24. Lu Y, Li T, Wei G, Liu L, Chen Q, Xu L, Zhang K, Zeng D and Liao R: The long non-coding RNA NEAT1 regulates epithelial to mesenchymal transition and radioresistance in through miR-204/ZEB1 axis in nasopharyngeal carcinoma. Tumour Biol 37: 11733-11741, 2016.

25. Alaiyan B, Ilyayev N, Stojadinovic A, Izadjoo M, Roistacher M, Pavlov V, Tzivin V, Halle D, Pan H, Trink B, et al: Differential expression of colon cancer associated transcript1 (CCAT1) along the colonic adenoma-carcinoma sequence. BMC Cancer 13: 196 , 2013.

26. Mizrahi I, Mazeh H, Grinbaum R, Beglaibter N, Wilschanski M, Pavlov V, Adileh M, Stojadinovic A, Avital I, Gure AO, et al: Colon cancer associated transcript-1 (CCAT1) expression in adenocarcinoma of the Stomach. J Cancer 6: 105-110, 2015.

27. Zhang XF, Liu T, Li Y and Li S: Overexpression of long non-coding RNA CCAT1 is a novel biomarker of poor prognosis in patients with breast cancer. Int J Clin Exp Pathol 8: 9440-9445, 2015.

28. Zhu H, Zhou X, Chang H, Li H, Liu F, Ma C and Lu J: CCAT1 promotes hepatocellular carcinoma cell proliferation and invasion. Int J Clin Exp Pathol 8: 5427-5434, 2015.

29. Ma MZ, Chu BF, Zhang Y, Weng MZ, Qin YY, Gong W and Quan ZW: Long non-coding RNA CCAT1 promotes gallbladder cancer development via negative modulation of miRNA-218-5p. Cell Death Dis 6: e1583, 2015.

30. He X, Tan X, Wang X, Jin H, Liu L, Ma L, Yu H and Fan Z: C-Myc-activated long noncoding RNA CCAT1 promotes colon cancer cell proliferation and invasion. Tumour Biol 35: 12181-12188, 2014. 